\title{
Synthesis of CdS/L-cys nanoparticles colloid solutions with predetermined optical properties
}

\author{
O.V. Krupko ${ }^{\text {a,b }}$, Yu. B. Khalavka ${ }^{\text {a,* }}$, L.P. Shcherbak ${ }^{\text {a }}$ \\ a Yuriy Fedkovych Chernivtsi National University 2, Kotsyubinsky Str., 58012 Chernivtsi, Ukraine \\ b Bukovinian State Medical University 2, Theatralna sq., Chernivtsi, 58000, Ukraine
}

\section{A R T I C L E I N F O}

Article history:

Received 5 December 2013

Received in revised form 28 July 2014

Accepted 16 August 2014

Available online 27 August 2014

\section{Keywords:}

A. Nanostructures

A. Semiconductors

B. Chemical synthesis

B. Luminescence

\begin{abstract}
A B S T R A C T
The purpose of this paper is to summarize experimental data of CdS/L-cystein nanoparticles (NPs) colloid solutions optical properties as function of 3-component mixture $\left(\mathrm{Cd}^{2+}-\mathrm{S}^{2-}-\mathrm{L}-\mathrm{cys}\right)$ content. The NPs synthesis was carried out at $\mathrm{pH} 11$ in the wide composition range based on literature data. The influence of the solutions composition on the colloids stability and the CdS/l-cys NPs size was monitored by absorption and fluorescence spectra observation at room temperature and studied by TEM. A polynomial model was used for the responses produced from Scheffe's simplex lattice design with fourth degree terms. The paper also compares the results of two statistical-experimental methods, namely 2D Scheffe's simplex-lattice design and 3D-plot by STATISTICA v6 program. Both models were found to be adequate for prediction the optical properties of the solutions but with various approximation levels.
\end{abstract}

() 2014 Elsevier Ltd. All rights reserved.

\section{Introduction}

CdS nanoparticles (NPs) capped by L-cystein have been extensively studied in the last decades due to their special electronic, catalytic and optical properties. The $\mathrm{Cd}^{2+}-\mathrm{S}^{2-}-\mathrm{L}-\mathrm{cystein}$ (L-cys) aqueous system composition, $\mathrm{pH}$, ionic strength usually are basic parameters that determine size, morphology and fluorescent properties of the NPs that give a possibility for their usage as fluorescent probes in many biological applications, for analytical purposes of d-elements cations detection, as very efficient and highly chemoselective photocatalysts etc. [1-19]. However, the choice of the system composition has been determined in various papers in empirical manner that complicates the possibility of the NP's properties change generalization and prediction at given content of the precursors.

Recently Barglic-Chory et al. [13] successfully used statistical design of experiments for mathematical description of CdS/L-cys NPs properties (namely, band gap energy) dependences on two experimental factors (the concentration of the stabilizer and sulfidation reagent) at $\mathrm{pH} 4$ and $\mathrm{pH} 8$.

The most frequent design of various experiments results for multicomponent systems belongs to simplex-lattice designs suggested by Scheffe [20]. The basis for such a simple mathematical presentation of experimental results is a previous uniform scatter of

\footnotetext{
* Corresponding author.

E-mail address: y.khalavka@chnu.edu.ua (Y. B. Khalavka).
}

the experimental points on the so-called simplex lattice. The number of design points to be performed for obtaining a definite order for a definite number of components. The purpose of this design is the empirical prediction of the response to any mixture of the components when the response depends only on the proportions of the components but not on the total amount of the mixture [20,21]. Using the method makes possible estimation of the properties of an entire system from a limited number of observations.

The aim of this paper is to study experimentally and to describe in the form of mathematical models the correlations "composition-optical properties" for the $\mathrm{Cd}^{2+}-\mathrm{S}^{2-}$-L-cys 3component mixture in a wide concentration range, and to determine stability of the CdS/L-cys NPs prepared in aqueous solutions at $\mathrm{pH} 11$, room temperature.

Note that according to the literature data the CdS/L-cys NPs were synthesized in most cases in inert atmosphere (in argon [6$8,11,13-15]$ or nitrogen $[1,3-5,9,19])$ to prevent oxidation of the Lcysteine ligands and sulfide-ions. On the contrary, our experiments were carried out without any special effort to prohibit contact of the liquids with atmospheric oxygen during both NPs synthesis and the prepared solutions storage.

\section{Experimental}

Cadmium(II) chloride hydrate $\mathrm{CdCl}_{2} \cdot 2.5 \mathrm{H}_{2} \mathrm{O}$, L-cysteine (Sigma-Aldrich), sodium sulfide hydrate $\mathrm{Na}_{2} \mathrm{~S} \cdot 9 \mathrm{H}_{2} \mathrm{O}$ and sodium hydroxide $\mathrm{NaOH}$ used in the study were analytical grade and used without further purification. The investigated colloids were 

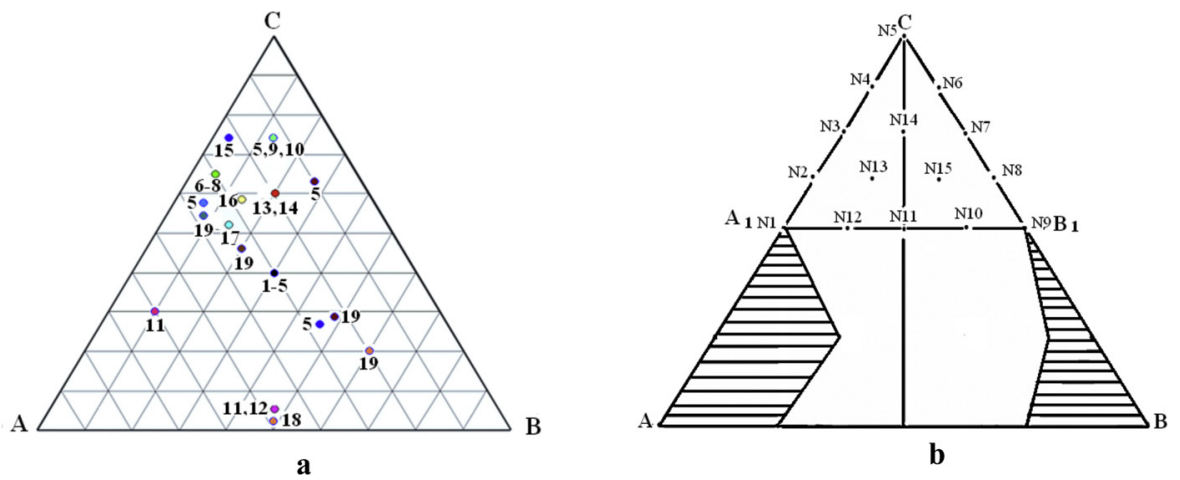

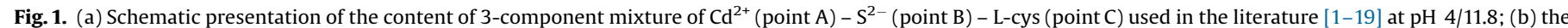
colloidal solutions instability ranges (shaded) and positions of 15 stable solutions researched in this paper in "small" composition triangle $A_{1} B_{1} C$ in the Scheffe's plan.

obtained using initial aqueous solutions with content of $\mathrm{Cd}^{2+}, \mathrm{S}^{2-}$ and L-cys equal to $0.5 \mathrm{M}, 0.5 \mathrm{M}$ and $0.05 \mathrm{M}$, respectively. After the $\left[\mathrm{Cd}(\mathrm{L}-\mathrm{cys})_{n}\right]^{2+}$ complexes preparation, the $\mathrm{pH}$ of the solution was adjusted to 11.0 with $0.5 \mathrm{M} \mathrm{NaOH}$ solution before the addition of calculated amount of the sodium sulfide solution. The reaction mixture was stirred vigorously with magnetic stirrer at room temperature during $0.5 \mathrm{~h}$. The $\mathrm{pH}$ of the solutions was measured by LIDA220 $\mathrm{pH}$-meter.

Two series of the CdS/L-cys NPs synthesis were performed. At first, the $\mathrm{Cd}^{2+}-\mathrm{S}^{2-}$-L-cys system composition range was determined according to the data [1-19] obtained at various $\mathrm{pH}$ ( $\mathrm{pH} 4$ to 11.8) that can be illustrated in the matrix by Scheffe's plan presented in Fig. $1 \mathrm{a}$ by a concentration triangle $A B C$. The experimental point's number from 1 to 19 corresponds to respective number in the Refs. list [1-19]. Coordinates of the triangle $\mathrm{ABC}$ are the following: $\mathrm{A}-60 \% \mathrm{Cd}^{2+}+30 \% \mathrm{~L}-\mathrm{cys}+10 \% \mathrm{~S}^{2-}$; $\mathrm{B}-10 \% \mathrm{Cd}^{2+}+30 \% \mathrm{~L}-$ cys $+60 \% \mathrm{~S}^{2-} ; \mathrm{C}-10 \% \mathrm{Cd}^{2+}+80 \% \mathrm{~L}-\mathrm{cys}+10 \%$ $\mathrm{S}^{2-}$. Thus, $\mathrm{Cd}^{2+}$ ions dominate in the $\mathrm{A}$ corner, $\mathrm{S}^{2-}$ ions in the $\mathrm{B}$ and L-cys in the $\mathrm{C}$ corner, correspondingly.

The experiments were realized according to the simplex-lattice design matrix for the fourth degree polynomial model $[20,21]$. Consequently, 15 reaction systems were prepared initially with the precursors' content ratio illustrated in Fig. 1b by the "large" triangle ABC. Since some colloidal solutions became unstable after few days (Fig. 1b, shaded area), a smaller concentration triangle $A_{1} B_{1} C$ was selected for more detailed investigation with smaller content of the precursors, namely, $\mathrm{A}_{1}-35 \% \mathrm{Cd}^{2+}+55 \% \mathrm{~L}$-cys $+10 \%$ $\mathrm{S}^{2-} ; \mathrm{B}_{1}-10 \% \mathrm{Cd}^{2+}+55 \% \mathrm{~L}-\mathrm{cys}+35 \% \mathrm{~S}^{2-}$. The composition of each solution and description of each point in the second series of experiments are given in Table 1.

Fourth power regression model has the form

$$
\begin{aligned}
y & =k_{1} x_{1}+k_{2} x_{2}+k_{3} x_{3}+k_{4} x_{1} x_{2}+k_{5} x_{1} x_{3}+k_{6} x_{2} x_{3} \\
& +k_{7} x_{1} x_{2}\left(x_{1}-x_{2}\right)+k_{8} x_{1} x_{3}\left(x_{1}-x_{3}\right)+k_{9} x_{2} x_{3}\left(x_{2}-x_{3}\right) \\
& +k_{10}\left(x_{1}-x_{2}\right)^{2} x_{1} x_{2}+k_{11}\left(x_{1}-x_{3}\right)^{2} x_{1} x_{3}+k_{12}\left(x_{2}-x_{3}\right)^{2} x_{2} x_{3} \\
& +k_{13} x_{1}^{2} x_{2} x_{3}+k_{14} x_{1} x_{2}^{2} x_{3}+k_{15} x_{1} x_{2} x_{3}^{2}
\end{aligned}
$$

where $y$ is the corresponding property ( $\lambda_{\text {edge, }}$ quantum yield, NP' of size in our case) and $\mathrm{k}_{i}$ are the coefficients calculated from the system of 15 equations based on the experimental data $[20,21]$.

The UV/vis spectra of the colloidal solutions were measured at room temperature by Ocean Optics USB-650 spectrometer in the range of $350-700 \mathrm{~nm}$. The NPs size was determined by the formula based on the equation (in assumption of the NPs sphericity)

$R=\frac{h}{\sqrt{\left(8 \mu \Delta E_{\mathrm{g}}\right)}}, \quad \mu=\left(\frac{1}{m_{\mathrm{e}}^{*}}+\frac{1}{m_{\mathrm{h}}^{*}}\right)^{-1}$

where $R$ is the radius, $h$ is the Planck constant; $m_{\mathrm{e}}$ is an electron rest mass, $m_{\mathrm{e}}{ }^{*}=0.21 m_{\mathrm{e}}, m_{\mathrm{h}}{ }^{*}=0.8 m_{\mathrm{e}}$ are electron and hole effective mass in CdS, correspondingly; $\Delta E_{\mathrm{g}}=E_{\mathrm{g}}$ (nano) $-E_{\mathrm{g}}$ (bulk). $E_{\mathrm{g}}$ (bulk) CdS taken as $2.4 \mathrm{eV}$. The $E_{\mathrm{g}}$ (nano) value was estimated using the $\mathrm{UV} /$ vis spectra data absorbance edge $\lambda_{\text {edge. }}$

The photoluminescence (PL) spectra were measured at room temperature with a PerkinElmer LS55 spectrophotometer with excitation wavelength $\lambda=360 \mathrm{~nm}$. To obtain the quantum yield

\begin{tabular}{|c|c|c|c|c|c|c|c|c|c|}
\hline \multirow[t]{2}{*}{ Point number no. } & \multicolumn{3}{|c|}{ Mixture composition $\left(\times 10^{4}\right), \mathrm{mol} \cdot \mathrm{L}^{-1}$} & \multicolumn{3}{|c|}{ Precursors' content, \% } & \multicolumn{3}{|l|}{ Properties } \\
\hline & $\mathrm{L}-\operatorname{cys}\left(\mathrm{x}_{1}\right)$ & $\mathrm{Cd}^{2+}\left(x_{2}\right)$ & $\left.S^{2-(} x_{3}\right)$ & $\mathrm{L}-\operatorname{cys}\left(\mathrm{x}_{1}\right)$ & $\mathrm{Cd}^{2+}\left(x_{2}\right)$ & $\mathrm{S}^{2-}\left(x_{3}\right)$ & $\lambda_{\text {edge, }}, \mathrm{nm}$ & $2 R$, nm by Eq. (2) & Quantum yield, \% \\
\hline $1\left(A_{1}\right)$ & 5.50 & 3.50 & 1.00 & 55.00 & 35.00 & 10.00 & 416 & 3.9 & 3.0 \\
\hline 2 & 6.12 & 2.87 & 1.00 & 61.25 & 28.75 & 10.00 & 406 & 3.7 & 5.0 \\
\hline 3 & 6.75 & 2.25 & 1.00 & 67.50 & 22.50 & 10.00 & 412 & 3.8 & 13.7 \\
\hline 4 & 7.37 & 1.63 & 1.00 & 73.75 & 16.25 & 10.00 & 416 & 3.9 & 26.4 \\
\hline $5(C)$ & 8.00 & 1.00 & 1.00 & 80.00 & 10.00 & 10.00 & 432 & 4.0 & 10.4 \\
\hline 6 & 7.37 & 1.00 & 1.63 & 73.75 & 10.00 & 16.25 & 438 & 4.5 & 12.4 \\
\hline 7 & 6.75 & 1.00 & 2.25 & 67.50 & 10.00 & 22.50 & 444 & 4.8 & 1.6 \\
\hline 8 & 6.12 & 1.00 & 2.87 & 61.25 & 10.00 & 28.75 & 450 & 5.0 & 5.8 \\
\hline $9\left(B_{1}\right)$ & 5.50 & 1.00 & 3.50 & 55.00 & 10.00 & 35.00 & 456 & 5.3 & 1.0 \\
\hline 10 & 5.50 & 1.63 & 2.87 & 55.00 & 16.25 & 28.75 & 430 & 4.3 & 7.2 \\
\hline 11 & 5.50 & 2.25 & 2.25 & 55.00 & 22.50 & 22.50 & 411 & 3.8 & 14.2 \\
\hline 12 & 5.50 & 2.87 & 1.63 & 55.00 & 28.75 & 16.25 & 408 & 3.7 & 10.1 \\
\hline 13 & 6.12 & 2.25 & 1.62 & 61.25 & 22.50 & 16.25 & 406 & 3.7 & 11.9 \\
\hline 14 & 6.75 & 1.62 & 1.62 & 67.50 & 16.25 & 16.25 & 428 & 4.2 & 26.5 \\
\hline 15 & 6.13 & 1.62 & 2.25 & 61.25 & 16.25 & 22.50 & 430 & 4.3 & 13.1 \\
\hline
\end{tabular}
(QY) of the NPs, an anthracene solution was used as a standard.

Table 1

Composition of solutions which correspond to 15 points of simplex-lattice Scheffe's plan for the composition triangle of $A_{1} B_{1} C$ and their properties 
Transmission electron microscopy (TEM) was used to image the as-grown CdS/L-cys NPs. To perform TEM a drop of sample has been deposited on the carbon coated copper grid. EM-420 electron microscope was used for the nanoparticles characterization.

\section{Results and discussion}

The spherical-like shape and rather small size $(1-6 \mathrm{~nm})$ of the NPs (eventually, quantum dots) from the solutions corresponded to the "small" composition triangle $A_{1} B_{1} C$ are illustrated in Fig. 2. The images confirm the possibility to calculate the NPs' size by Eq. (2), using the absorbance spectra data and demonstrate satisfactory accordance of both of the size estimation methods. The NPs size distribution histograms (in the insets) show relatively low polydispersity of the colloid solutions.

The CdS/L-cys NPs kinetic growth was monitored by spectroscopic data in a period of over ten days for determination of the growth process end. The UV/vis spectra of the colloidal solutions were also controlled periodically during 18 months for observation of the long-term solutions stability. As shown above, substantial excess of one of the crystal-forming ions at small content of the stabilizer (concentration triangle $A B C$, see Fig. $1 \mathrm{~b}$ ) leads to instability of the colloid solutions. Formed at these conditions NPs quickly reached to $10-20 \mathrm{~nm}$ that soon caused their aggregation and precipitation. In general, most stable solutions are observed at $\left[\mathrm{Cd}^{2+}\right] /\left[\mathrm{S}^{2-}\right]$ ratio close to stoichiometry.

More detailed investigations were performed with 15 stable compositions marked as composition triangle $A_{1} B_{1} C$ in Fig. $1 \mathrm{~b}$. The absorbance edge shift to longer wavelengths of the tested solutions was observed in time range $1-24 \mathrm{~h}$. The stabilized $\lambda_{\text {edge }}$ data are listed in Table 1 . Each $\lambda_{\text {edge }}$ data in Table 1 is the average value determined from triplicate experiments which were rather reproducible (standard deviations do not exceed $0.7 \%$ ).

Typical optical absorbance and PL-emission spectra of the CdS/Lcys NPs solutions are displayed in Fig. $3 a$ and b. They indicated 7 days evolution of the absorbance spectra with multiple peaks corresponding to various sizes of NPs that occurred in two mixtures with equal deviation from equimolar $\left[\mathrm{Cd}^{2+}\right] /\left[\mathrm{S}^{2-}\right]$ ratio (points 13 and 15 in the $A_{1} B_{1} C$ triangle, see Fig. $1 \mathrm{~b}$ and Table 1 ). As one can see excess of Cd-ions above stoichiometry (solution 13) had resulted in smaller $\lambda_{\text {edge }}$ value (and correspondingly NPs size) in comparison with the same sulfur-ions excess case (solution 15).

It can be noted that almost all absorbance spectra initially had demonstrated bimodal distribution of the conventionally "small"
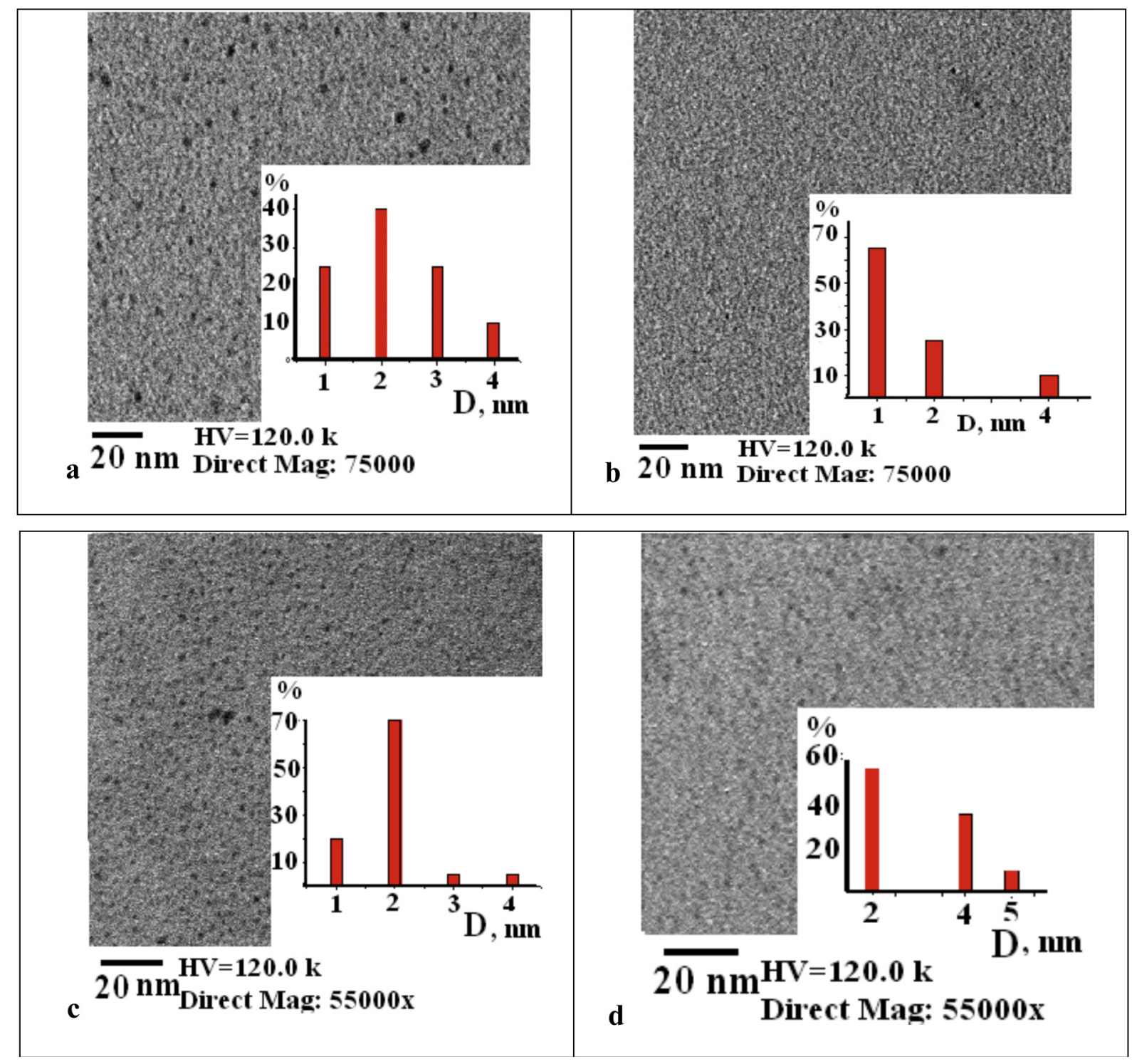

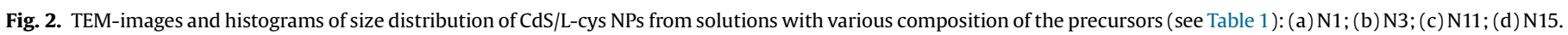



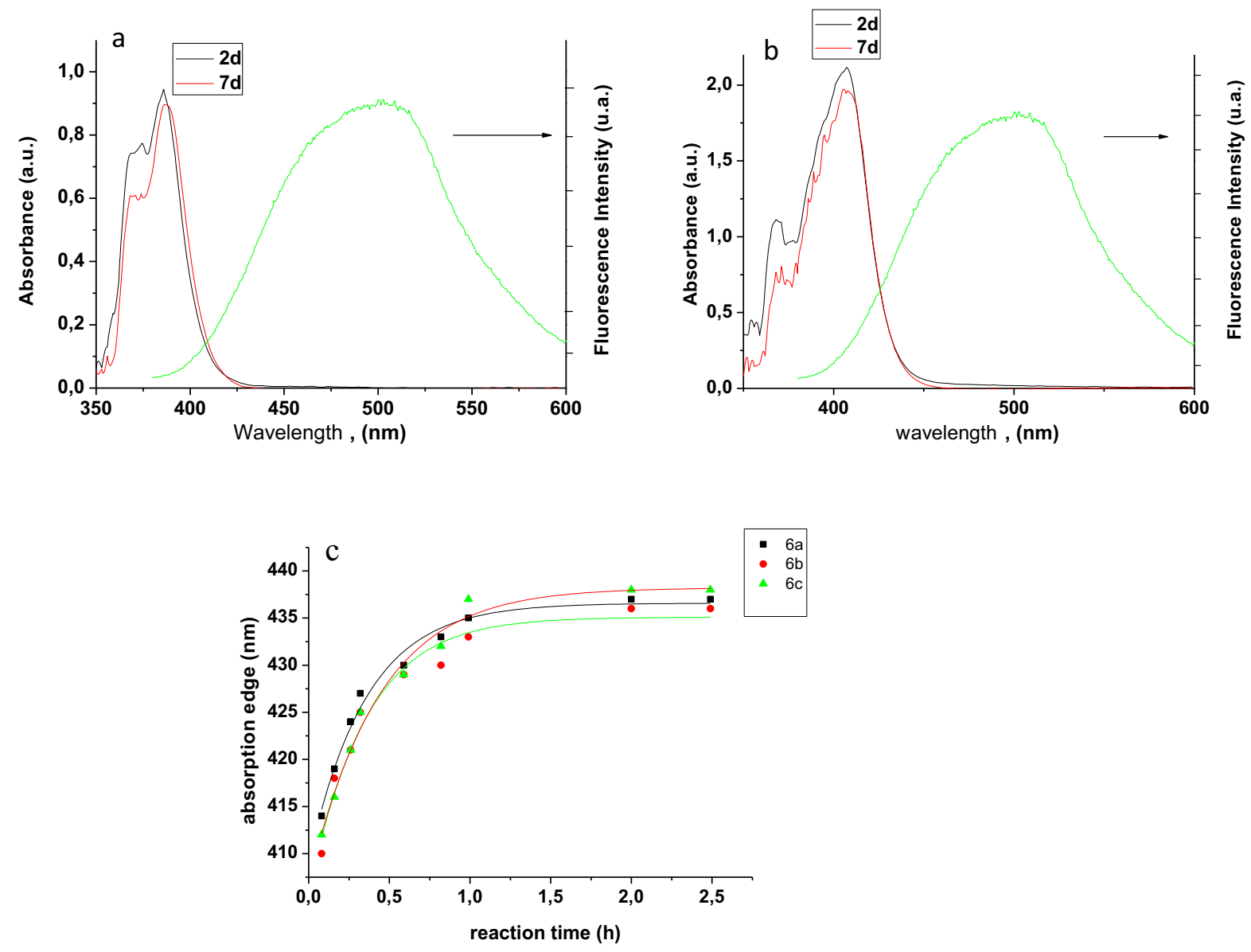

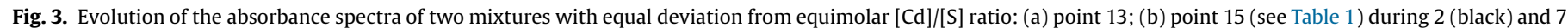

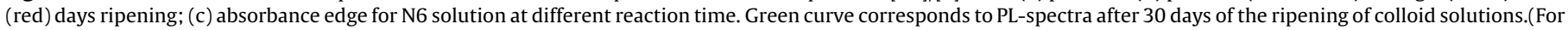
interpretation of the references to color in this figure legend, the reader is referred to the web version of this article.)

and "large" NPs'. The first absorption peak at $370 \pm 1 \mathrm{~nm}$ corresponding to smallest NPs was recorded a few days after the synthesis and disappeared later. The smallest NPs' size was estimated to be less than 1-2 nm in all cases. The characteristic absorbance peak of the "large" NPs in all spectra had stabilized in a few hours while $\lambda_{\text {edge }}$ varied within $432 \pm 24 \mathrm{~nm}$ that corresponded to $2 R=4.4 \pm 0.6 \mathrm{~nm}$.

The smallest NPs probably occurs due to slow decomposition of a part of primarily existing complexes $\left[\mathrm{Cd}(\mathrm{L}-\mathrm{Cys})_{n}\right]^{2+}$, followed by further formation of such NPs. The largest NPs are formed, obviously, by Ostwald ripening mechanism consuming the smallest ones.

The $\left[\mathrm{Cd}^{2+}\right] /\left[\mathrm{S}^{2-}\right]$ ratio also influences the growth kinetics of the NPs. At the same content of the stabilizer Cd-rich conditions provide essentially faster growth of the "large" NPs in comparison with S-rich solutions. Fig. $3 c$ illustrates kinetics of the $\lambda_{\text {edge }}$ longwave shift in solution N6 with sulphide-ions excess, high content of L-cys. The data can be treated according to the LaMer mechanism, which suggests a short burst of nucleation followed by slow diffusive growth, favoring formation of mono-disperse crystalline nanoparticles.

Taking into account that the largest NPs correspond to higher value of the semiconductor band gap, it is of interest to obtain analytical description of interrelation between the precursor's composition and the optical absorbance edge position $\left(\lambda_{\text {edge }}\right)$ for the $\mathrm{A}_{1} \mathrm{~B}_{1} \mathrm{C}$ triangle.

The experimental data can be fitted by the fourth degree polynomials as

$$
\begin{aligned}
\lambda_{\text {edge }} & =4320.537 x_{1}+416 x_{2}+456 x_{3}-48 x_{1} x_{2}+0.5 x_{1} x_{3} \\
& -100 x_{2} x_{3}+10 x_{1} x_{2}\left(x_{1}-x_{2}\right)+x_{1} x_{3}\left(x_{1}-x_{3}\right) \\
& -10 x_{2} x_{3}\left(x_{2}-x_{3}\right)-85\left(x_{1}-x_{2}\right)^{2} x_{1} x_{2} \\
& +0.5\left(x_{1}-x_{3}\right)^{2} x_{1} x_{3}+\left(x_{2}-x_{3}\right)^{2} x_{2} x_{3}+618 x_{1}^{2} x_{2} x_{3} \\
& -794 x_{1} x_{2}^{2} x_{3}+400 x_{1} x_{2} x_{3}^{2}
\end{aligned}
$$

where $x_{1}, x_{2}$ and $x_{3}$ are content (in part of unity) of L-cys, $\mathrm{Cd}^{2+}$ and $\mathrm{S}^{2-}$, respectively.

A similar approach was used according to the experimental quantum yield (QY) value of the prepared 15 solutions after their properties stabilization that leads to the following fourth degree polynomial

$$
\begin{aligned}
\mathrm{QY} & =10.4 x_{1}+3 x_{2}+1 x_{3}+28 x_{1} x_{2}-16.4 x_{1} x_{3}+48.8 x_{2} x_{3} \\
& +94.4 x_{1} x_{2}\left(x_{1}-x_{2}\right)+10.1 x_{1} x_{3}\left(x_{1}-x_{3}\right) \\
& +10.1 x_{2} x_{3}\left(x_{2}-x_{3}\right)+80\left(x_{1}-x_{2}\right)^{2} x_{1} x_{2} \\
& +138\left(x_{1}-x_{3}\right)^{2} x_{1} x_{3}-53.3\left(x_{2}-x_{3}\right)^{2} x_{2} x_{3}+885.3 x_{1}^{2} x_{2} x_{3} \\
& -321.6 x_{1} x_{2}^{2} x_{3}-62.9 x_{1} x_{2} x_{3}^{2}
\end{aligned}
$$

Fig. 4a visualizes estimated by Eq. (3) correlations with the $\lambda_{\text {edge }}$ isolines step in $5-10 \mathrm{~nm}$ (black numbers). One can see that the influence of deviation of the crystal-forming ions content from stoichiometry on the NPs' optical properties is asymmetrical. In general, at equal content of the stabilizer excess of the sulfide-ions causes a larger batochromic shift in comparison with the same quantity of $\mathrm{Cd}^{2+}$-ions.

The design of the Eq. (4) (Fig. 4b) illustrates the system composition influence on the NPs quantum yield. At stoichiometric ratio of $\left[\mathrm{S}^{2-}\right] /\left[\mathrm{Cd}^{2+}\right]$ increase of the $\mathrm{L}$-cys concentration 

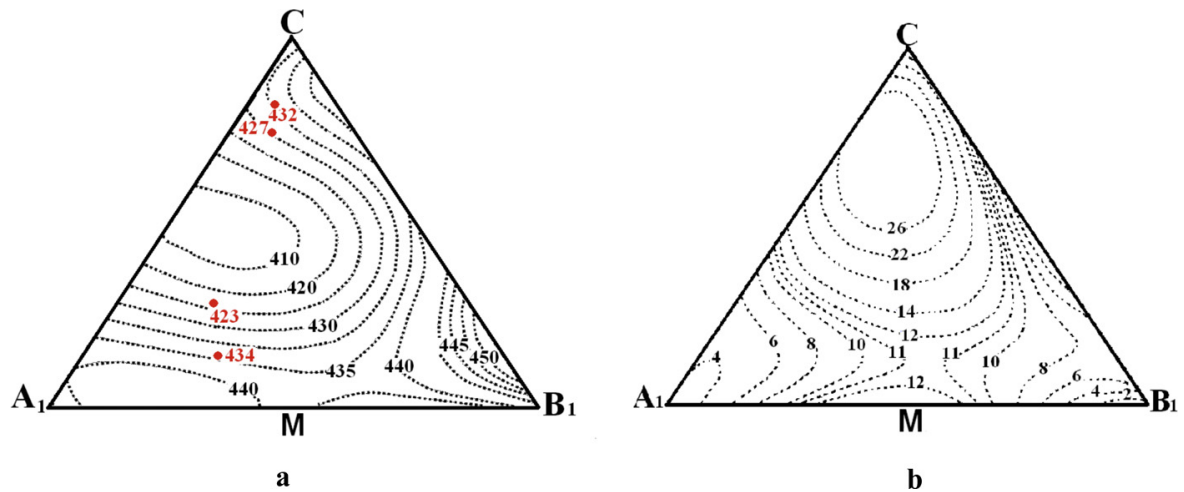

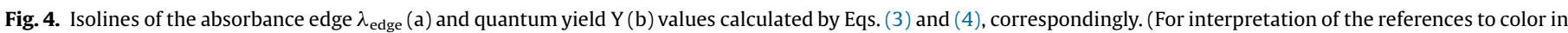
text, the reader is referred to the web version of this article.)

Table 2

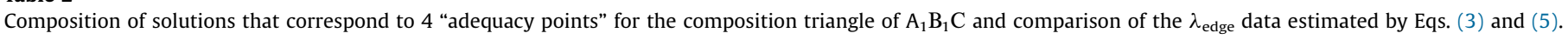

\begin{tabular}{|c|c|c|c|c|c|c|}
\hline No. of specimen (adequacy point) & [L-cys] $\left(x_{1}\right)$ & {$\left[\mathrm{Cd}^{2+}\right]\left(x_{2}\right)$} & {$\left[\mathrm{S}^{2-}\right]\left(x_{3}\right)$} & $\lambda_{\text {edge, }}$ exp., $\mathrm{nm}$ & 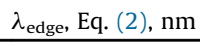 & $\lambda$ edge, Eq. (5), $\mathrm{nm}$ \\
\hline $1 \mathrm{a}$ & 0.70 & 0.15 & 0.15 & $432 \pm 3$ & 430 & 424 \\
\hline $2 a$ & 0.64 & 0.23 & 0.13 & $423 \pm 2$ & 424 & 417 \\
\hline $3 a$ & 0.68 & 0.21 & 0.11 & $427 \pm 2$ & 425 & 419 \\
\hline $4 a$ & 0.58 & 0.23 & 0.19 & $434 \pm 3$ & 428 & 420 \\
\hline
\end{tabular}

appropriately caused increase of the solutions QY up to $26 \%$. Deviation from equimolar $\left[\mathrm{Cd}^{2+}\right] /\left[\mathrm{S}^{2-}\right]$ ratio in both directions decreases the solutions' quantum yield demonstrating a negative role of the surface defects as the traps.

To test the adequacy of Eqs. (3) and (4) four solutions were specially performed ("adequacy points", see Table 2) with other concentration of the components than the ones presented in Table 1. They show high adequacy of the calculated by Eq. (3) values to the experimental data, demonstrating difference less than 1-6 nm (Fig. 4a, red numbers, large points).

It is of interest to analyze the obtained experimental data using other experimental-statistical methods, for instance by STATISTICA v6 [22]. The last is the universal computer-integrated system intended for the statistical analysis and visualization of information.

As this program does not limit the number of experimental data and their coordinates for description, the experimental results both of the 15 basic points (see Table 1 ) and 4 additional ones (the adequacy points, Table 2) were used. Unfortunately, this program allows fitting not higher than the third order polynom:

$$
\begin{aligned}
\lambda_{\text {edge }} & =431 x_{1}+416 x_{2}+455 x_{3}-59 x_{1} x_{2}+5 x_{1} x_{3}-97 x_{2} x_{3} \\
& -30 x_{1} x_{2}\left(x_{1}-x_{2}\right)-4 x_{1} x_{3}\left(x_{1}-x_{3}\right)-26 x_{2} x_{3}\left(x_{2}-x_{3}\right) \\
& +85 x_{1} x_{2} x_{3}
\end{aligned}
$$

The results are illustrated in Fig. 5. Comparison of the 3-factors correlations of $\lambda_{\text {edge }}$ shown in Figs. 4 a and 5 a show that the $\lambda_{\text {edge }}$ values estimated by both Eqs. (3) and (5) coincide in general, though deviation from experimental data is remarkably higher in the third order approximation case (see Table 2). This correlation can be even better visualized in 3D-plot of the STATISTICA v6. software.

Comparing plots of Figs. $4 a$ and $5 a$, one can see that both approaches demonstrate reversible dependence of the $\lambda_{\text {edge }}$ values

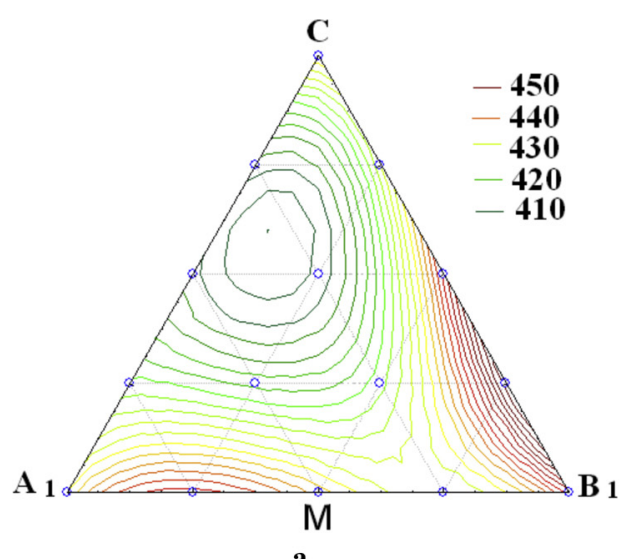

a

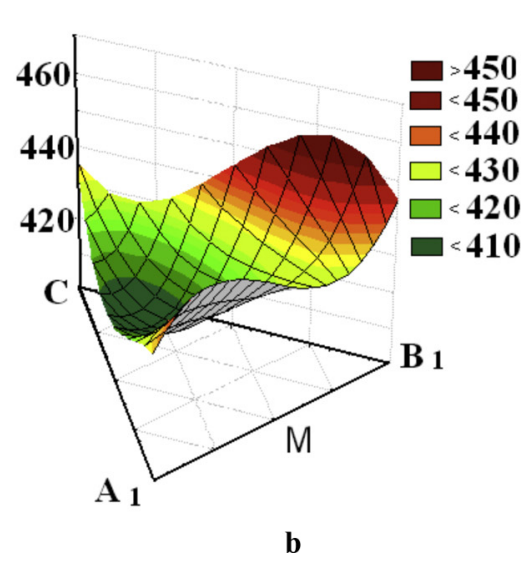

b

Fig. 5. Estimated by Eq. (5) isolines of absorbance edge (a) and 3D-view of this solution (b). 
on the capping agent concentration when $\left[\mathrm{Cd}^{2+}\right]$ and $\left[\mathrm{S}^{2-}\right]$ are equal (CM section). The NPs' maximal size diminishes (proportionally to the $\lambda_{\text {edge }}$ ) with L-cys content increasing at small [L-cys] following by increase when the [L-cys]/[C $\left.\mathrm{Cd}^{2+}\right]$ relation reaches 4 . Obviously this fact means that part of the $\mathrm{Cd}^{2+}$-ions exist in rather stable complexes $\left[\mathrm{Cd}(\mathrm{L}-\mathrm{Cys})_{4}\right]^{2+}$ with the coordination number $(n)$ of 4 that slowly disintegrate during the initial stage of the synthesis. Such interpretation can also explain existence of two peaks in the "fresh" absorbance spectra which transform into single peak with time during the NPs ripening. Thus one can conclude that minimal NPs size is obtainable at precursor-ions content ratio $[\mathrm{L}-\mathrm{cys}] /\left[\mathrm{Cd}^{2+}\right]=4,\left[\mathrm{Cd}^{2+}\right]=\left[\mathrm{S}^{2-}\right]$.

The deviation of $\left[\mathrm{Cd}^{2+}\right] /\left[\mathrm{S}^{2-}\right]$ from stoichiometry are resulted in adverse effect. At low content of the capping agent, excess of the Cd-ions demonstrate tendency to diminish the NPs' size while the sulfur-ions excess remarkable stimulated their growth. Probably, after the decomposition of $\left[\mathrm{Cd}(\mathrm{L}-\mathrm{Cys})_{n}\right]^{2+}$ complexes due to formation of very stable compound (and, accordingly, nanocrystal $\mathrm{CdS}$ ) the last is surrounded by sufficient amount of the capping agent for reduction the NPs size.

\section{Conclusion}

The systematic study of stability and optical properties (absorption and photoluminescence at room temperatures) of synthesized at $\mathrm{pH} 11 \mathrm{CdS} / \mathrm{L}$-cys nanoparticles were performed with the precursors' concentration varying within the wide composition range, according to found in literature. The NPs size variation is obtained within $1-30 \mathrm{~nm}$, demonstrates the instability of the solutions with large excess of crystal-forming ions, low content of the capping agent.

The composition range of the colloid solutions stability was determined $\left(\left[\mathrm{Cd}^{2+}\right]\right.$ and $\left[\mathrm{S}^{2-}\right]$ from $(1.0$ to 3.5$) \times 10^{-4} \mathrm{~mol} \cdot \mathrm{L}$; [ $\mathrm{L}-$ cysteine] from (5.5 to 8$) \times 10^{-4} \mathrm{~mol} \cdot \mathrm{L}^{-1}$ ) providing the smallest particles (up to $6 \mathrm{~nm}$ ) formation. These solution composition parameters were estimated using Scheffe's simplex-lattice design.

Numerical correlations between $\mathrm{Cd}^{2+}, \mathrm{S}^{2-}$ ions and L-cys concentrations and absorption edge $\left(\lambda_{\text {edge }}\right)$, the CdS/L-cys nanoparticles size $(2 R)$, quantum yield (QY) of the obtained colloidal solutions have been determined by two statistical-experimental methods. Illustrated by 2D (according to Scheffe's simplex-lattice design) and by 3D (according to STATISTICA v6 program) images of the obtained correlations showed a satisfactory agreement with the additional control data (the adequacy points). Both models were found to be adequate in general for the prediction of certain mixture ratios when the desired optical properties are achievable and vice versa.

The smallest formed at $\mathrm{pH} 11 \mathrm{CdS} / \mathrm{L}$-cys particles $(2 R=3.7 \mathrm{~nm}$, $\left.\lambda_{\text {edge }}=406 \mathrm{~nm}\right)$ are obtained at the precursors ratio $\left[\mathrm{S}^{2-}\right] /\left[\mathrm{Cd}^{2+}\right] /[\mathrm{L}-$ cys] $=1: 2.9: 6.1$, the largest ones $\left(2 R=5.3 \mathrm{~nm}, \lambda_{\text {edge }}=456 \mathrm{~nm}\right)$ are formed when $\left[\mathrm{S}^{2-}\right] /\left[\mathrm{Cd}^{2+}\right] /[\mathrm{L}-\mathrm{cys}]=3.5: 1.0: 5.5$. Maximal $\mathrm{QY}=26 \%$ of the stable solutions can be reached by the precursors content ratio near $\left[\mathrm{S}^{2-}\right] /\left[\mathrm{Cd}^{2+}\right] /[\mathrm{L}-\mathrm{cys}]=1.0: 1.6: 7.4$.

The obtained results will help to choose better synthetic strategies for the formation of semiconductor nanoparticles with precisely tuned properties.

\section{Acknowledgements}

This publication is based on the work supported by a grant from the U.S Civilian Research \& Development Foundation (CRDF Global) (Grant agreement UKC2-7071-CH-12), State Agency on Science, Innovation and Informatization of Ukraine (Grant agreement M/148-2013), and State Fund of Fundamental Research (Grant agreement GP/F49/151).

\section{References}

[1] J.-L. Chen, C.-Q. Zhu, Functionalized cadmium sulfide quantum dots as fluorescence probe for silver ion determination, Anal. Chim. Acta 546 (2005) 147-153.

[2] M.N. Kalasad, M.K. Rabinal, B.G. Mulimani, Facile synthesis of bioconjugated fluorescent CdS nanoparticles of tunable light emission, J. Phys. D Appl. Phys. 43 (2010) 305301-305307.

[3] Y. Chen, Z. Rosenzweig, Luminescent CdS quantum dots as selective ion probes, Anal. Chem. 74 (19) (2002) 5132-5138.

[4] J. Chen, A. Zheng, Y. Gao, C. He, Functionalized CdS quantum dots-based luminescence probe for detection of heavy and transition metal ions in aqueous solution, Spectrochim. Acta Part A 69 (2008) 1044-1052.

[5] W.B.K. Abdullah, R.K. Mehra, Cysteine-mediated synthesis of CdS bionanocrystallites, Chemosphere 37 (2) (1998) 363-385.

[6] A. Priyam, A. Chatterjee, S.K. Das, A. Saha, Synthesis and spectral studies of cysteine-capped CdS nanoparticles, Res. Chem. Intermed. 31 (7-8) (2005) 691-702.

[7] A. Chatterjee, A. Priyam, S.C. Bhattacharya, A. Saha, pH dependent interaction of biofunctionalized CdS nanoparticles with nucleobases and nucleotides: a fluorimetric study, J. Lumin. 126 (2007) 764-770.

[8] D. Ghosh, S. Ghosh, A. Saha, Quantum dots based probing of mannitol: an implication in clinical diagnostics, Anal. Chim. Acta 675 (2010) 165-169.

[9] T.L. Sounart, P.A. Safier, J.A. Voigt, J. Hoyt, D.R. Tallant, C.M. Matzke, T.A. Michalske, Spatially-resolved analysis of nanoparticle nucleation and growth in a microfluidic reactor, Lab Chip 7 (2007) 908-915.

[10] K.M. Mullaugh, G.W. Luther III, Growth kinetics and long-term stability of CdS nanoparticles in aqueous solution under ambient conditions, J. Nanopart. Res. 13 (2011) 393-404.

[11] D.P.S. Negi, T.I. Chanu, Surface-modified CdS nanoparticles as a fluorescent probe for the selective detection of cysteine, Nanotechnology 19 (465) (2008) 503-465507.

[12] X.-L. Liu, Y.-J. Zhu, A precursor nanowire template route to CdS nanowires, Mater. Lett. 63 (2009) 1085-1088.

[13] Ch. Barglik-Chory, Ch. Remenyi, H. Strohm, G. Müller, Adjustment of the band gap energies of biostabilized CdS nanoparticles by application of statistical design of experiments, J. Phys. Chem. 108B (2004) 7637-7640.

[14] Ch. Barglik-Chory, A.F. Münster, H. Strohm, Ch. Remenyi, G. Müller, Influence of synthesis parameters on the growth of CdS nanoparticles in colloidal solution and determination of growth kinetics using Karhunen-Loeve decomposition, Chem. Phys. Lett. 374 (2003) 319-325.

[15] Z.-X. Cai, H. Yang, Y. Zhang, X.-P. Yan, Preparation, characterization and evaluation of water-soluble L-cysteine-capped-CdS nanoparticles as fluorescence probe for detection of $\mathrm{Hg}(\mathrm{II})$ in aqueous solution, Anal. Chim. Acta 559 (2006) 234-239.

[16] N.G. Piven, L.P. Shcherbak, P.I. Feychuk, S.M. Kalytchuk, S.G. Kryliouk, D.V. Korbutyak, Thermostimulated effects of cadmium sulfide nanoparticles synthesis, Kondensirovannye sredy I mezhfaznye granitsy (In Russ.) 8 (4) (2006) 315-319.

[17] J. Sapra, D. Sarma, G. Hodes, Blue emission from cystein ester passivated cadmium sulfide nanoclusters, Chem. Commun. Is. 21 (2001) 2188-2189.

[18] G.A. Martinez-Castaňón, J.P. Loyola-Rodriquez, J.F. Reyes-Macias, N. NiňoMartinez Facundo Ruiz, Synthesis and optical properties of functionalized CdS nanoparticles with different sizes, Superf. Vacio 23 (4) (2010) 1-4.

[19] B.R. Lewandowski, A.T. Kelley, R. Singleton, J.-R. Li, M. Lowry, I.M. Warner, J.C. Garno, Nanostructures of cysteine-coated CdS nanoparticles produced with two-particle lithography, J. Phys. Chem. C 113 (15) (2009) 5933-5940.

[20] H. Scheffe, Experiments with mixture, J. R. Stat. Soc. B20 (1958) 344-360.

[21] R. Živorad Lasič, Design of experiments in chemical engineering, A Practical Guide, Wiley-VCH Verlag GmbH \& Co., 2004.

[22] http://www JTstatsoft.ru/products/STATISTICA_Advanced/. 